\title{
Painful subcutaneous nodule of the arm
}

\author{
Fabio Becce • Emilie Uldry • Igor Letovanec • \\ Nicolas Theumann $\cdot$ Jean-Yves Meuwly
}

Received: 8 February 2012 /Revised: 4 April 2012 / Accepted: 5 April 2012 /Published online: 14 May 2012

(C) ISS 2012

\section{Part II}

\section{Diagnosis}

Extradigital glomus tumor (subcutaneous glomus tumor of the arm).

\section{Discussion}

The diagnostic approach to superficial soft-tissue masses is challenging. These may be categorized as mesenchymal tumors, skin appendage lesions, metastatic tumors, or inflammatory lesions [1]. The differential diagnosis should first be limited by considering the age and gender of the patient, as well as the detailed anatomic location of the lesion (extremity, trunk, or head and neck; and cutaneous,

Fabio Becce and Emilie Uldry contributed equally to this work.

The case presentation can be found at doi:10.1007/s00256-012-1415-4.

F. Becce $(\bowtie) \cdot$ J.-Y. Meuwly

Department of Diagnostic and Interventional Radiology, Centre

Hospitalier Universitaire Vaudois, University of Lausanne,

Rue du Bugnon 46,

1011 Lausanne, Switzerland

e-mail: fabio.becce@chuv.ch

E. Uldry

Department of Visceral Surgery,

Centre Hospitalier Universitaire Vaudois, University of Lausanne, 1011 Lausanne, Switzerland

\section{Letovanec}

University Institute of Pathology,

Centre Hospitalier Universitaire Vaudois,

1011 Lausanne, Switzerland

\section{N. Theumann}

Department of Radiology, Clinique Hirslanden Bois-Cerf, 1006 Lausanne, Switzerland subcutaneous or fascial) [1, 2]. It may further be restricted by taking into account the salient clinical manifestations and imaging findings [2]. By applying this approach to our case, the main differential diagnosis consisted of peripheral nerve sheath tumor (schwannoma, neurofibroma), angiolipoma, leiomyoma cutis (including piloleiomyoma and angioleiomyoma), eccrine
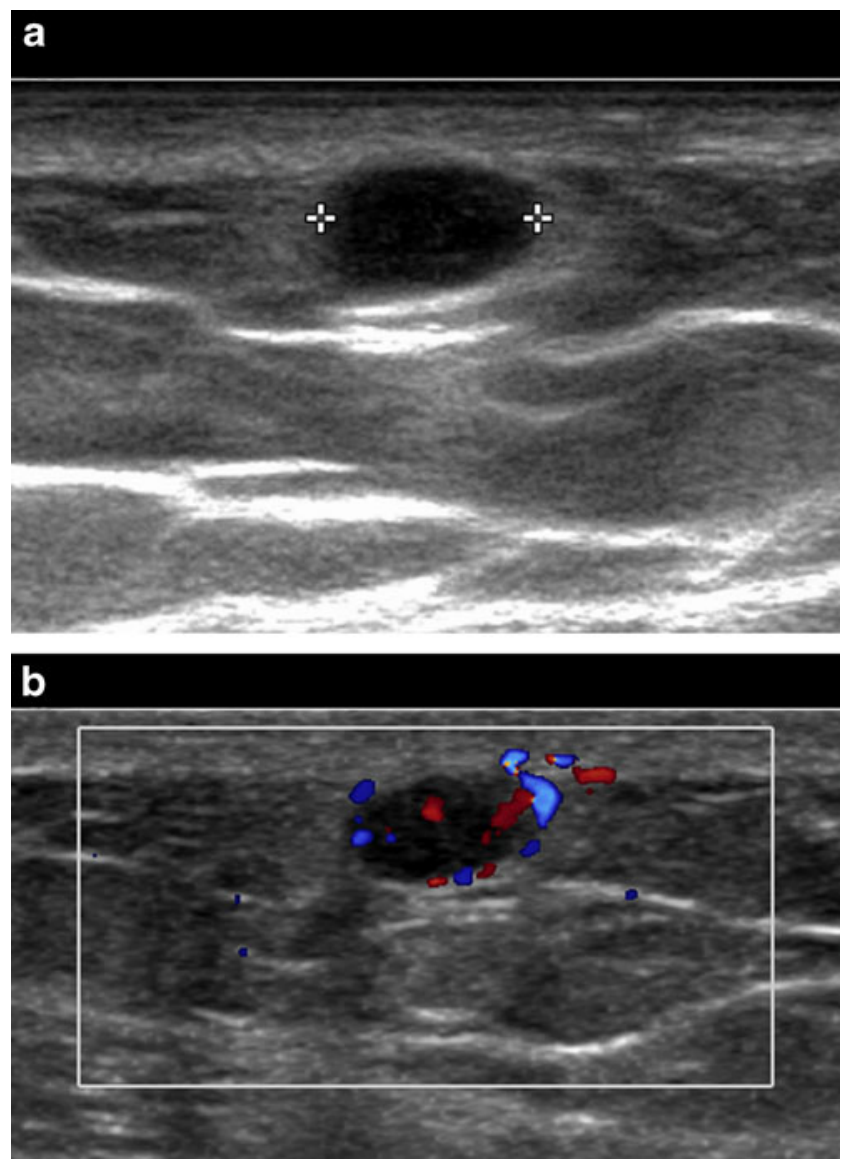

Fig. 1 Longitudinal a B-mode and b color Doppler US images (17-5 $\mathrm{MHz}$ linear probe) of the lateral aspect of the right arm 
Fig. 2 Axial a T1-weighted

(repetition time/echo time, 573/

11), b fat-suppressed (FS) T2weighted (5770/86) and c gadolinium-enhanced FS T1weighted (621/11) turbo spinecho MR images of the right arm d Coronal maximum-intensity projection (MIP)

FS T1-weighted (2.8/1.1) gradient -recalledecho MR angiographic view of the right arm, in the early arterial phase $(16 \mathrm{sec})$
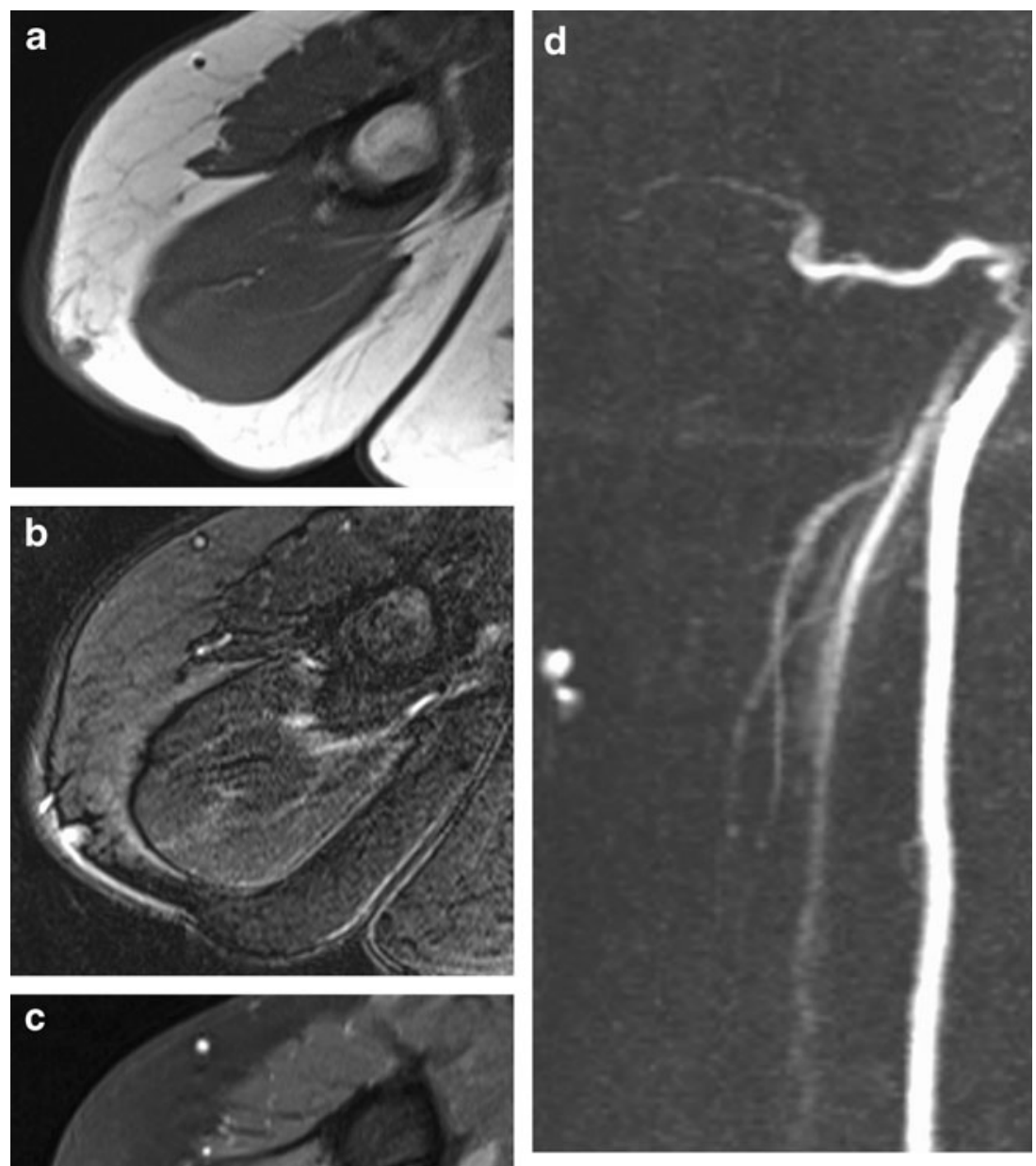

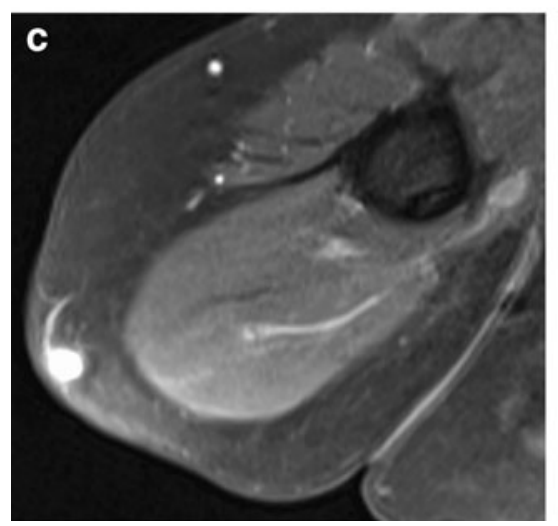

spiradenoma, and glomus tumor [1, 2]. First, although the distinctive imaging features of peripheral nerve sheath tumors, such as depiction of the nerve entering or exiting the tumor, are difficult to assess in superficial lesions [1], the presented lesion was not in the territory of a major nerve. In addition, the fact that it was hypersensitive to cold should have directed the diagnosis towards a glomus tumor or leiomyoma cutis [2-4]. However, the latter occurs more commonly in middle-aged women and predominantly in lower extremities. Second, angiolipomas typically have a heterogeneous pattern with areas of high signal intensity on T1- and T2-weighted images [1, 2]. They often exhibit areas of recent hemorrhage. Besides, apart from those five painful subcutaneous lesions, other primary or secondary neoplasms (such as benign or malignant fibrous histiocytoma, leiomyosarcoma, or melanoma metastasis) might be considered. However, these are not tender. Therefore, despite being in an extradigital location, a glomus tumor was the most likely diagnosis.

Glomus tumors are benign perivascular neoplasms arising from the smooth muscle cells of neuromyoarterial glomus bodies $[3,4]$. They account for about $2 \%$ of soft-tissue tumors of extremities, and represent between 1 and $5 \%$ of all upper extremity neoplasms [3, 5]. While a female predominance $(2: 1$ to $3: 1)$ has been noted for digital tumors, extradigital neoplasms are more common in men (greater than 4:1) [3, 5]. Glomus tumors can occur at any age, although predominantly between the third to fifth decades of life for digital and the fourth to seventh for extradigital neoplasms [3]. They tend to be solitary and can occur in virtually any organ of the body. The hands are involved in up to $75 \%$ of cases, with a subungual location in 50 to $65 \%$ of those [3-5]. 
Fig. 3 a Gross pathologic examination demonstrates the glomus tumor lying within the subcutaneous fat, just below the epidermal and dermal skin layers. b Histopathological examination reveals sheets of bland medium-sized cells surrounding vessels of variable size (H\&E stain; original magnification $\times 100$ ). $\mathbf{c}$ The glomus tumor is extremely rich in reticulin (original magnification $\times 100$ ). d Immunohistochemical analysis reveals numerous glomus cells that stain strongly for smooth-muscle actin (original magnification $\times 20$ )
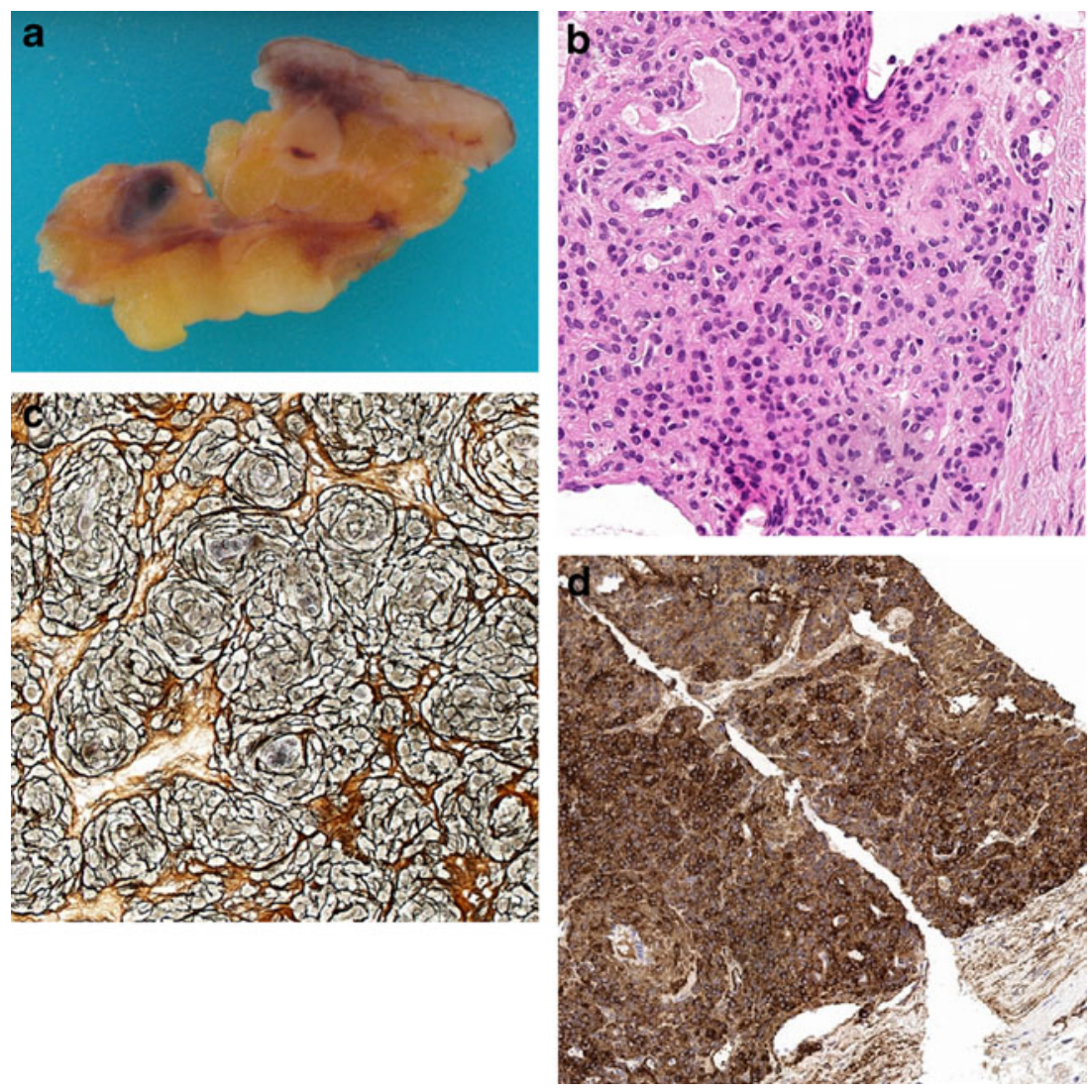

Depending on the varying proportion of glomus cells, blood vessels and smooth muscle tissue, glomus tumors are categorized as glomus tumor proper, glomangioma, and glomangiomyoma, respectively [6, 7]. Microscopic examination reveals clusters of monomorphous cells with rounded nuclei and scant eosinophilic cytoplasm (Fig. 3b) [7]. Besides, these tumors are extremely rich in reticulin (Fig. 3c) [7]. At immunohistochemistry, glomus cells typically stain for smooth muscle actin (Fig. 3d) and vimentin, as opposed to vascular neoplasms whose endothelial cells are immunoreactive for CD31, CD34, and factor VIII [6, 7]. Malignant transformation (glomangiosarcoma) is exceedingly rare but should be considered when the tumor presents atypical features, such as large size (greater than $2 \mathrm{~cm}$ ), deep location, infiltrative growth pattern, mitotic activity, nuclear pleomorphism, and necrosis [8].

The clinical features of glomus tumors vary with their location. While digital tumors exhibit the classic clinical triad of paroxysmal pain, localized tenderness and hypersensitivity to cold in 63 to $100 \%$ of cases, these findings are much less common with extradigital neoplasms [3, 4]. On physical examination, they tend to manifest as small bluish subungual or subcutaneous nodules that are exquisitely tender to touch. Extradigital lesions have a less specific presentation, which often leads to misdiagnosis and/or long delay in diagnosis [3].
The imaging findings of glomus tumors also depend on their location (digital vs. extradigital; and soft-tissue vs. bone). Conventional radiographs are usually normal but a small scalloped bony defect may be seen when the tumor is adjacent to bone [4]. In contrast, a well-defined radiolucent area with sclerotic margins is noted with intraosseous tumors [4]. Owing to its high spatial resolution, US is helpful to assess superficial glomus tumors. These appear as well-circumscribed, solid, hypoechoic lesions surrounded by a capsule, with marked intralesional vascularity on color and power Doppler US examination (Fig. 1a,b) [4, 9]. Recently, the "vascular stalk sign" was reported to be visible

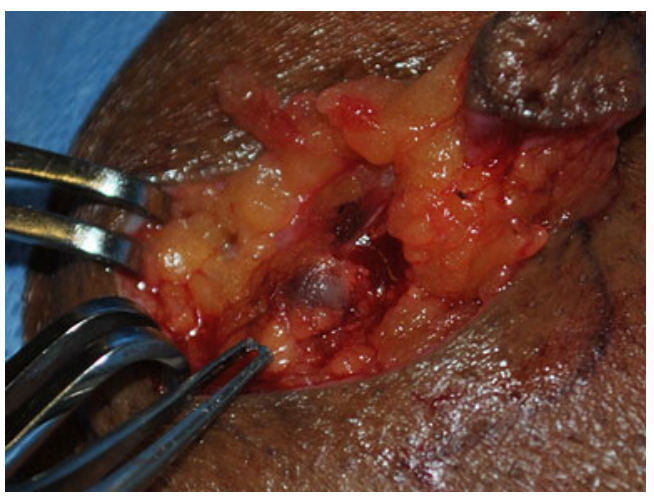

Fig. 4 Intraoperative view depicts the subcutaneous glomus tumor, of bluish color, with its vascular pedicle 
in $67 \%$ of extradigital lesions on color Doppler US [9]. This corresponds to the presence of prominent vascular flow connecting the lesion to adjacent soft-tissue (Fig. 1b) [9]. Computed tomography is generally used in the work-up of deep (thoracic, abdominal, or intraosseous) glomus tumors [4]. Magnetic resonance is the imaging modality of choice owing to its high sensitivity $(82-100 \%)[4,10]$. The lesions are typically of low or intermediate signal intensity on T1and high signal intensity on T2-weighted images, with strong enhancement after intravenous gadolinium administration (Fig. 2a-d) [4, 10].

Surgery is the treatment of choice for glomus tumors $[3,5]$. Due to their small size and frequent superficial location, these neoplasms can be readily and fully excised (Figs. 3a and 4), with instant relief of symptoms. However, recurrences have been reported in 12 to $33 \%$ of cases [3]. Therapeutic options consist primarily in punch or shave biopsy [3].

In conclusion, a high index of suspicion is mandatory to promptly and accurately make the diagnosis of extradigital glomus tumors. These benign perivascular neoplasms should be included in the differential diagnosis of painful subcutaneous nodules, particularly when the clinical triad of paroxysmal pain, localized tenderness, and hypersensitivity to cold is present.

\section{References}

1. Beaman FD, Kransdorf MJ, Andrews TR, Murphey MD, Arcara LK, Keeling JH. Superficial soft-tissue masses: analysis, diagnosis, and differential considerations. Radiographics. 2007;27:50923.

2. Wu JS, Hochman MG. Soft-tissue tumors and tumorlike lesions: a systematic imaging approach. Radiology. 2009;253:297-316.

3. Schiefer TK, Parker WL, Anakwenze OA, Amadio PC, Inwards CY, Spinner RJ. Extradigital glomus tumors: a 20-year experience. Mayo Clin Proc. 2006;81:1337-44.

4. Glazebrook KN, Laundre BJ, Schiefer TK, Inwards CY. Imaging features of glomus tumors. Skeletal Radiol. 2011;40:855-62.

5. Soule EH, Ghormley RK, Bulbulian AH. Primary tumors of the soft tissues of the extremities exclusive of epithelial tumors: an analysis of five hundred consecutive cases. AMA Arch Surg. 1955;70:462-74.

6. Bahk WJ, Mirra JM, Anders KH. Intraosseous glomus tumor of the fibula. Skeletal Radiol. 2000;29:708-12.

7. Gombos Z, Zhang PJ. Glomus tumor. Arch Pathol Lab Med. 2008; 132:1448-52.

8. Folpe AL, Fanburg-Smith JC, Miettinen M, Weiss SW. Atypical and malignant glomus tumours: analysis of 52 cases, with a proposal for the reclassification of glomus tumours. Am J Surg Pathol. 2001;25:1-12.

9. Park HJ, Jeon YH, Kim SS, et al. Gray-scale and color Doppler sonographic appearances of nonsubungual soft-tissue glomus tumors. J Clin Ultrasound. 2011;39:305-9.

10. Drapé JL, Idy-Peretti I, Goettmann S, et al. Subungual glomus tumors: evaluation with MR imaging. Radiology. 1995;195:507-15. 